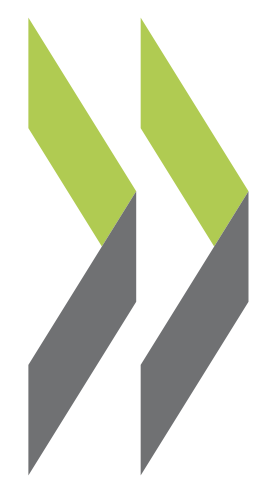

CELE Exchange, Centre for Effective Learning Environments 2011/03

Transforming Pedagogical Ethos into an Effective Learning Environment
Jens Guldbaek,

\author{
Hanna Bohn Vinkel,
} Mie Guldbaek Broens 


\section{Transforming pedagogical ethos into an effective} learning environment

By Jens Guldbaek, Hanna Bohn Vinkel and Mie Guldbaek Broens, LOOP*, Denmark

The world has been changing so fast that educational systems have not had time to keep pace. We therefore need to rethink, renew and modernise our schools, as well as develop a new educational experience for children. In order to do this, it is crucial that we devise a new approach to developing our educational systems. This article proposes a novel way of generating new ideas, based on empirical knowledge.

\section{THE CHALLENGE}

Today's children are growing up in a rapidly changing world and they will need to keep learning throughout life. The competences we should help children develop are how to learn, to be creative, to experiment, communicate, take responsibility, work together and exchange opinions. Far-reaching changes are therefore needed in the educational system: instead of being standardised, what we really need is personalised learning. To paraphrase Sir Ken Robinson, a standardised educational system is as bad for a person's development as fast food is to your long-term health.

\section{WHERE DO WE BEGIN?}

A popular quote circulating on the Internet these days by author Maria Robinson states that "Nobody can go back and start a new beginning, but anyone can start today and make a new ending." The ideal "ending", the kind of learning we would like to have in our school system, was very different when our current educational system was established. It does not fit the world we live in today. We simply can't lead the future by reproducing what we did in the past. We need to move on from traditional ways of thinking and dare to try new things. We need a new "ending": we need to rethink, renew and modernise our entire school system.

We should start by paying attention to the way we plan ahead and handle the process of change. Usually when we plan, not only do we want to have all the elements at hand, we also base our planning on what we already know. However, if we want to develop, we need to combine experience with new knowledge and fresh assumptions. Future school projects should take a critical look at the way we habitually proceed and find a balance between what we know and do not know - yet. 
We need to keep in mind that a development project is a process, not a race. There is no finishing line because our educational systems are never finished products. They must constantly evolve to fit their time. They can - and should - have goals, but once these are reached, new goals will appear. The motto of the Danish teachers' union is "Learning is for life, not for school" and we should keep this in mind in all aspects of school and education.

When we develop schools our starting point should be what we know about how people learn. It is common knowledge that the best way to learn is by doing, by participating and being active in the process. When you teach others you retain about $90 \%$ of the subject matter, in comparison to $50 \%$ if you discuss the subject and only $30 \%$ if you watch a demonstration. Therefore it is the teacher, not the student, who learns the most in traditional classroom teaching. The classroom and the way a learning situation is organised within it is a strongly established concept all over the world. We tend to find one teacher, one class and one classroom, with the teacher, standing in front of the students, giving his or her version of things. Chimamanda Adichie, a Nigerian novelist, warns us that if we only hear a single story we risk a critical misunderstanding. If we only hear a single story about another person or culture we risk becoming ignorant and ignorance is the route to intolerance. If you transpose Adichie's theory into the world of education, it is important that all subjects be taught by more than one teacher.

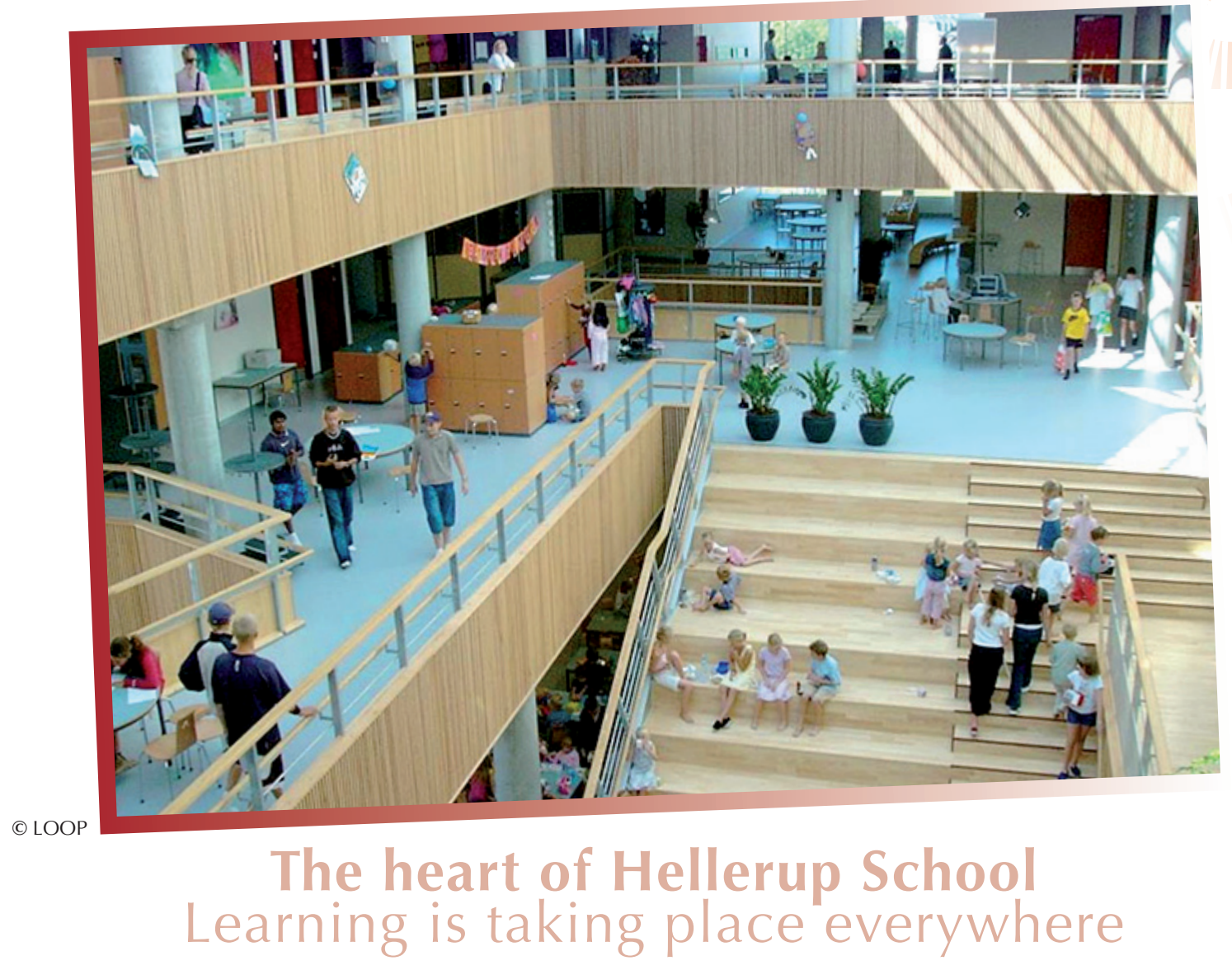




\section{THE FOUR ELEMENTS TO CONSIDER IN SCHOOL DEVELOPMENT}

When society became so complex that it had to take over some of the educational roles traditionally assured by role models at home, it began to create schools which would secure future development. When we at LOOP work on school development we always take into account the following four elements: The Society, The Child, The Future and The School. Here are some questions we have learned to consider in relation to each one. The list is not exhaustive and, again, one should always be open to new thinking along the way.

\section{The Society}

What kind of society is the school going to reflect? What sort of culture will the school be part of? What characterises our society, and what does all this demand of our school? Do we have any new experiences that can give us clues as how to organise the school?

\section{The Child}

In relation to children we need to be clear about what set of values we are working with. We need to make sure that every decision is based on that set of values. What is our view of human nature and learning? Do we have any new knowledge about children and learning that we need to take into account?

\section{The Future}

The future is an odd element to work with because it is notoriously difficult to predict. Although everybody can make a guess as to what it will bring, it is important to try to look ahead and to accept that it is going to be different and it is going to be influenced by what we do today. When we look at the competences that are currently expected of the workforce (i.e. the ability to see things from a wide perspective, the ability to be a good team player, to enjoy responsibility, have excellent communication skills, be flexible and able to work successfully in a fast-paced environment) we owe it to ourselves and our children to ask whether it is really possible to develop these kinds of competences in today's traditional schools.

\section{The School}

All of these considerations necessarily have consequences for the school system. First, learning should meet the individual needs of each child. Second, we know that children are entering a rapidly changing world and that the knowledge they acquire today is different from the skills they will need in ten years when they leave school - therefore they must be able to keep on learning. So learning how to learn, to be creative, experiment, communicate, disseminate, take responsibility, work together, exchange and respectfully discuss opinions are some of the competences we must seek to develop. In traditional schools we need to shift the focus by 180 degrees, from teachers being responsible for teaching and students being responsible for learning to the teacher being responsible for understanding children's individual learning needs and supporting them. The focus needs to be on the child's learning process.

\section{MIND THE GAP}

This is not news, but there is still a big gap between what we know to be good learning conditions and what we offer in practice in current educational environments all over the world. In order to narrow the gap between what we know and what we do, we might want to look at the decision-making process. 
Usually most decisions are made at the beginning of a development project, so as to be on top of things. However, this is severely limiting. The kind of decisions that we make at that stage are based on old knowledge. A development process based only on old ideas is a contradiction in terms, but sadly this is often the way it happens.

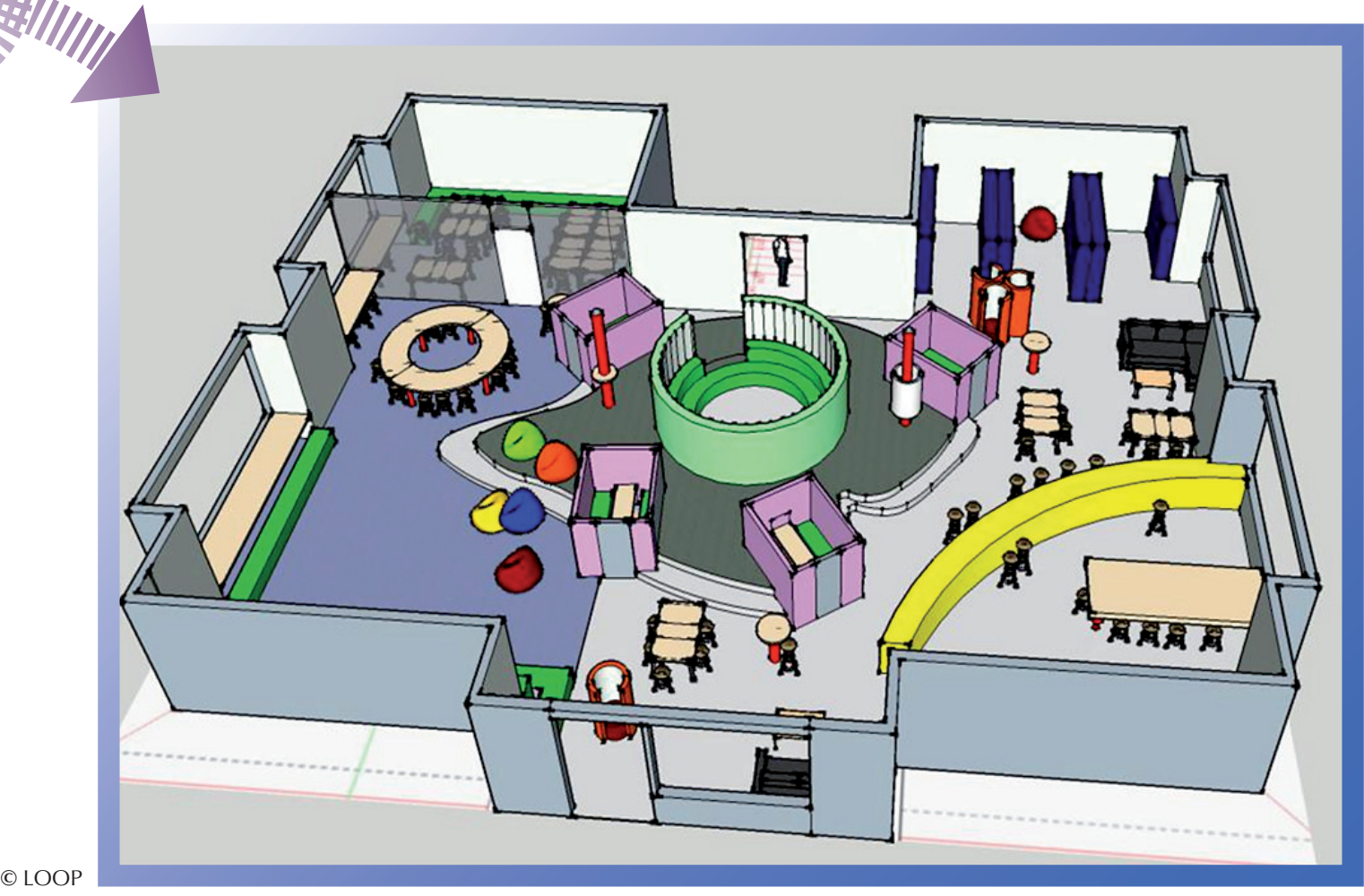

\section{A learning environment developed with 12-year-old pupils from Maglegaards School: a classroom, a study, a workshop, a studio box and an auditorium for 75 pupils}

We in LOOP have come up with a possible recipe for giving new ideas a chance to develop and become an integral part of the project. We suggest that decision makers should try to limit their decisions purely to the immediate next step, and then follow the flow of the project. They should make the decisions that allow the project dialogue to move forward and in such a way that new knowledge can be generated through discussions with all stakeholders. It is only when actors are open to others' viewpoints and engage openly in conversation that new knowledge will be able to emerge. As dialogue evolves, it constantly regenerates ideas and enhances them with new knowledge. This knowledge emerges from exchanges and is developed in co-ownership between all stakeholders. Another suggestion is that projects should be coached rather than planned, and people should be coached rather than others trying to plan for them. 


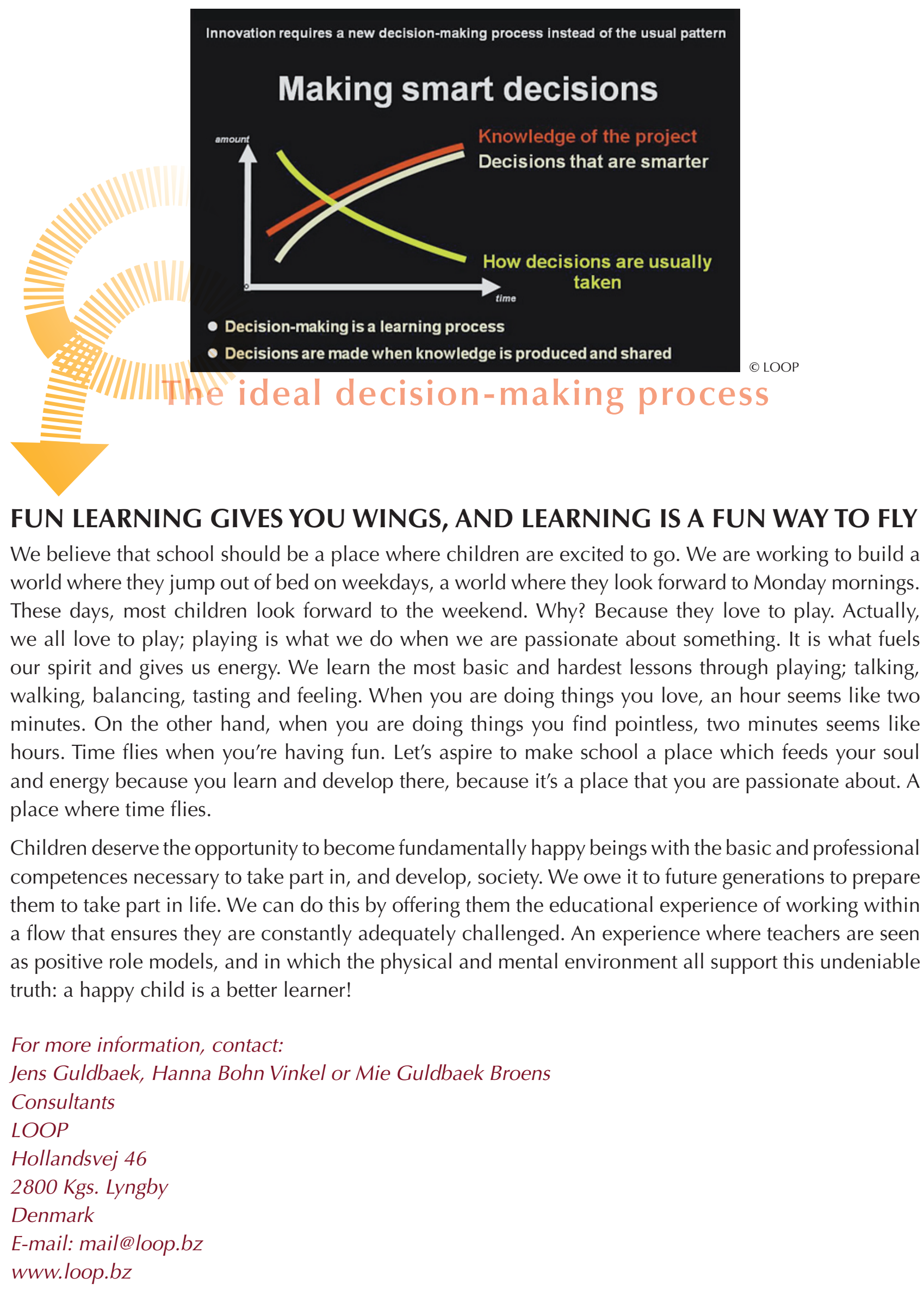




\section{ORGANISATION FOR ECONOMIC CO-OPERATION AND DEVELOPMENT}

The OECD is a unique forum where governments work together to address the economic, social and environmental challenges of globalisation. The OECD is also at the forefront of efforts to understand and to help governments respond to new developments and concerns, such as corporate governance, the information economy and the challenges of an ageing population. The Organisation provides a setting where governments can compare policy experiences, seek answers to common problems, identify good practice and work to co-ordinate domestic and international policies.

The OECD member countries are: Australia, Austria, Belgium, Canada, Chile, the Czech Republic, Denmark, Estonia, Finland, France, Germany, Greece, Hungary, Iceland, Ireland, Israel, Italy, Japan, Korea, Luxembourg, Mexico, the Netherlands, New Zealand, Norway, Poland, Portugal, the Slovak Republic, Slovenia, Spain, Sweden, Switzerland, Turkey, the United Kingdom and the United States. The European Commission takes part in the work of the OECD.

OECD Publishing disseminates widely the results of the Organisation's statistics gathering and research on economic, social and environmental issues, as well as the conventions, guidelines and standards agreed by its members.

This work is published on the responsibility of the Secretary-General of the OECD. The opinions expressed and arguments employed herein do not necessarily reflect the official views of the Organisation or of the governments of its member countries. 